\title{
POLÍTICAS CONTEMPORÂNEAS DE FORMAÇÃO DE PROFESSORES PARA OS ANOS INICIAIS DO ENSINO FUNDAMENTAL
}

\author{
IRIA BRZEZINSKI*
}

\begin{abstract}
RESUMO: Realizar uma discussão sobre as políticas de formação inicial e continuada de professores para os Anos Iniciais do Ensino Fundamental (AIEF) e analisá-las no contexto da educação brasileira contemporânea é um dos desafios, que me imponho como objetivo deste artigo, em decorrência das pesquisas que venho desenvolvendo neste campo. Em face desta opção, outros desafios aqui se impõem na medida em que precisam ser discutidas também questóes externas à formação inicial e continuada de professores, mas que interferem na qualidade da educação básica brasileira, entre elas a regulação e avaliação pelo Estado da formação de professores por meio de certificação de competências e a criação de um órgão regulador da profissão, por integrantes da categoria profissional de professor.

Palavras-chave: Políticas educacionais. Formação inicial e continuada de professores. Professor dos anos iniciais do ensino fundamental. Certificação de competências.
\end{abstract}

\section{CONTEMPORARIES POLICIES OF TEACHER EDUCATION FOR THE EARLY YEARS OF ELEMENTARY SCHOOL}

ABSTRACT: Based on research conducted by the author, this paper discusses the policies for the initial and continuing education of people who will teach the first grades of elementary school in the context of Brazilian contemporary education. Such an option brings other challenges forth, since external issues, which interfere in the quality of Brazilian education, need to be discussed. These regard the

Professora titular da Universidade Católica de Goiás (UCG) e presidente da Associação Nacional pela Formação dos Profissionais da Educação (ANFOPE). E-mail: iria@ucg.br 
initial and continuing education of teachers and include regulation, the State assessment of teacher education through skill certification, and the creation of a national regulatory agency by members of this profession.

Key words: Educational policies. Teacher's initial and continuing education. Teacher of the elementary school early years. Skills certification.

\section{Questôes introdutórias}

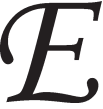

m nosso país, a formação inicial de professores para os AIEF, na letra da lei, ${ }^{1}$ deve ser realizada no curso de Pedagogia, na Escola Normal Superior e na modalidade Normal do Ensino Médio. A formação continuada, por sua vez, se fará em diferentes modalidades e agências formadoras, segundo um princípio norteador da Lei n. 9.394/ 1996 - educação ao longo da vida - reafirmado em seu artigo $1^{\circ}$, que traduz a concepção de educação abrangente dos processos formativos "que se desenvolvem na vida familiar, na convivência humana, no trabalho, nas instituiçôes de ensino e pesquisa, nos movimentos sociais e organizações da Sociedade Civil e nas manifestações culturais”.

O objetivo do presente trabalho é discutir as políticas de formação inicial e continuada de professores para os AIEF e analisá-las no contexto contemporâneo da educação brasileira. É um dos desafios que me imponho em decorrência das pesquisas que desenvolvo neste campo. Em face dessa opção, é significativo trazer questões que, embora externas à formação inicial e continuada de professores, interferem na qualidade da educação básica (EB) e no profissionalismo docente.

Com efeito, abordo a certificação de competências ${ }^{2}$ como um dos processos de regulaçãa e avaliação proposto pelo Estado, como controle de formação e exercício profissional do professor. Abordo também estudos e discussões que têm sido feitos acerca da criação de um órgão regulador da profissão-professor, organizado à semelhança de um conselho ou ordem profissional e coordenado por profissionais da educação.

A discussão aqui anunciada implica explicitar a natureza do objeto, políticas educacionais de formação inicial e continuada de professores, e apreender o seu desenvolvimento. Inicio, assim, do entendimento de 
que a formação do professor é uma prática pedagógica, na qual se articulam teoria e prática e, por isso, é práxis. Nesse sentido, considero importante circunscrever as políticas anteriormente referidas aos contextos em que foram elaboradas e aprofundar questões que, embora não sejam específicas da formação docente, integram a atuação profissional do professor, pois assim o objeto será tratado realmente como é.

Tal discussão requer, ainda, revelar com que projeto de sociedade, educação, cultura e formação de professores estou sintonizada, tendo em vista que há mais de um projeto que sustenta as políticas de formação de professores para a escola básica pública. Ademais, é bastante visível a tensão entre dois projetos que convivem em disputa na arena de poder das políticas educacionais. De um lado, está o projeto da sociedade política, defendido pelos tecnocratas, que em seus discursos enfatizam a qualidade social da formação do professor, entretanto colocam em prática os princípios da qualidade total. De outro lado, encontra-se o da sociedade civil organizada em entidades educacionais reunidas no movimento nacional de educadores, cuja luta tem por princípio a qualidade social para formar docentes que atuará na educação básica.

É preciso esclarecer que, embora para mim, todas as entidades educacionais alinhadas aos parâmetros da qualidade social na educação sejam dignas de respeito, compartilho princípios das que vêm desenvolvendo ações conjuntas e esboçam uma organização em rede. ${ }^{3}$ São elas: Associação Nacional pela Formação dos Profissionais da Educação (ANFope), Associação Nacional de Pós-Graduação e Pesquisa em Educação (ANPEd), Associação Nacional de Política e Administração da Educação (ANPAE) o Centro de Estudos Educação e Sociedade (CEDES) e pelo Fórum de Diretores das Faculdades de Educação das Universidades Públicas Brasileiras (FORUNDIR).

Essas entidades defendem um projeto de sociedade, de educação, de formação de professores e de escola fundamentado na concepção histórico-social e que tem como paradigma educacional as relações entre cultura, sociedade e educação. Esse paradigma leva em conta as transformações sociais, das forças produtivas e do mundo do trabalho, transformações que, dialeticamente, provocam mudanças no papel social atribuído ao professor. Diante da adoção desse paradigma, a formação do profissional da educação para atuar na educação básica é entendida como um processo marcado pela complexidade do 
Políticas contemporâneas de formação de professores para os anos iniciais...

conhecimento, pela crítica, pela reflexão-ação, pela criatividade, pelo reconhecimento da identidade cultural dos envolvidos nos processos formativos e pelas relações estabelecidas na mediação entre formadores e aprendentes.

Em sintonia com princípios, propostas, ideais e bandeiras de luta das supracitadas entidades, adoto a premissa de que a formação inicial de professores deve ser feita na universidade, lócus do "universo da teoria, do rigor dos conceitos e dos métodos historicamente produzidos, da liberdade, da criação, da produção do novo, da ética (...)" (Coêlho, 1996, p. 36).

Aprendi com Coêlho que se formar na universidade é mais do que profissionalizar-se. $\mathrm{O}$ trabalho de formação realizado por esta instituição tem por fim:

(...) desenvolver no indivíduo a capacidade de - em sua vida pessoal, em sociedade, no mundo do trabalho, em qualquer outra situação em que se encontre - entender e transformar o real, fazer a história, realizar a transcendente aspiração do homem para a liberdade, para a contemplação do verdadeiro, do belo, do justo. (1996, p. 35)

Por essa mesma razão, os educadores engajados na rede de associações defendem que a ambiência universitária é o espaço mais adequado para formar o profissional da educação. Esses educadores consideram que é na universidade, lugar do trabalho não-material, que o professor poderá preparar-se para o domínio do trabalho pedagógico, cujo ponto de partida e de chegada é a prática social.

A educação, "entendida como mediação no seio da prática social" (Saviani, 2007, p. 110), é trabalho não-material, porque se insere no plano das "idéias, conceitos, valores, símbolos, hábitos, atitudes, habilidades" (idem, 1996, p. 146). No espaço universitário o estudante desenvolve sua trajetória de formação e vai construindo, coletivamente, o tornar-se professor e pesquisador. Essa é uma forma rigorosa de pensar, refletir, criar, enfim, apreender e socializar o conhecimento já acumulado pela humanidade, produzir novos conhecimentos acerca do campo específico de seu interesse, além dos saberes do campo pedagógico e do saber político da ciência que irá ensinar.

$\mathrm{O}$ atual ministro da Educação Fernando Haddad tem, exatamente, atribuído à universidade o papel de formar professores em cursos 
presenciais. Ocorre, entretanto, que as políticas educacionais adotadas pelo seu Ministério e financiadas por órgãos internacionais contradizem os discursos de Haddad, quando estimulam a oferta de cursos a distância, para formar professores na Universidade Aberta do Brasil (UAB) a fim de que, até 2010 , seja coberto o déficit de 250.000 professores para a EB.

Vale a pena lembrar que não tem passado a largo dos educadores engajados em redes críticas ao modelo atual de formação oferecido pela universidade. Ele precisa ser redimensionado para corresponder às exigências da EB, alicerce do sistema educacional. No Brasil de muitos "brasis", a importância da diversidade de lócus de formação de professores não tem sido também ignorada pelos educadores, porém alertam que a diversidade é solução transitória e que a universidade deverá constituir a instituição, por excelência, de formação inicial de todos os profissionais da educação, a ser ministrada em cursos presenciais.

Felizmente, se há diversos lócus dedicados à preparação do professor, existe também uma forte influência das Diretrizes Curriculares Nacionais para a Licenciatura em Pedagogia ((Parecer CNE/CP n. 5, de 13/12/2005, e na Resolução CNE/CP n. 1, de 15/5/2006), que têm provocado uma reconfiguração das instituições de preparação docente.

Nesse artigo, entretanto, atenho-me especialmente ao curso de Pedagogia. Inicialmente, porém, explicito algumas concepções de formação, de formação inicial e continuada de professores e de profissionalismo docente, o que farei no item seguinte.

É, contudo, especialmente ao curso de Pedagogia que pretendo ater-me neste artigo. Inicialmente, porém, explicito algumas concepções de formação, de formação inicial e continuada de professores e de profissionalismo docente, o que farei no item a seguir.

Concepções de formação, de formação inicial e continuada de professores e profissionalismo docente

Fundamento-me, sobretudo, nas idéias de Garcia (1999), que discute a problemática como um processo que inclui referências conceituais e teorias a respeito de formação, de formação de professores e de profissão docente. Essa multirreferencialidade deve contemplar os procedimentos de investigação que estudam, entre outros, a epistemologia da 
Políticas contemporâneas de formação de professores para os anos iniciais...

educação, as teorias pedagógicas, o preparo para o trabalho docente, a escola de ensino fundamental, o local de ação do professor, o projeto político-pedagógico como estratégia de intervenção de seus construtores e o processo de aprendizagem como atribuição precípua do trabalho docente.

A palavra "formação" é susceptível de múltiplas interpretações. De origem latina, vem de formatione, que significa ato, efeito, modo de formar. Como consta em Houaiss (2001, p. 1.372), o termo reporta-se "ao conjunto de conhecimentos e habilidades específicos a um determinado campo de atividade prática ou intelectual”.

Para Carreira (1999, p. 29), "o conceito formação está ligado a uma lógica da prática, à produção [do sujeito que se forma] e deve ter em conta a identidade do formando, as suas representaçôes sociais, afectivas e culturais”. Nestes termos, teoria e prática, saber e ação necessitam articular-se no processo de formação, assim como no trabalho docente as concepções de sociedade, homem, educação, o conhecimento específico e as habilidades operativas, técnicas e tecnológicas não se separam.

Garcia (1999, p. 19) revisou em vários autores o conceito formação. Honoré (1980) concebe formação, em geral, associada a alguma atividade. Também pode ser concebida como processo de desenvolvimento que se realiza em decorrência de maturação interna do sujeito e da aprendizagem.

Apesar de serem múltiplas as acepções de formação, Ferry (1987) destaca que a formação de professores possui uma natureza específica e apresenta particularmente três traços distintivos de qualquer outra formação: a) é uma dupla formação, pois, simultaneamente, é acadêmicocientífica e pedagógica; b) é uma formação profissional, porquanto tem por finalidade formar pessoas que irão se dedicar à profissão-professor; c) constitui formação de formadores, porque se desenvolve em um espaço em que se realiza a formação de quem se forma ao mesmo tempo em que ocorre a prática profissional do formador.

Em virtude de o exercício do magistério nos AIEF requerer domínio do saber multidisciplinar e uma prática unodocente que conferem identidade ao professor, é necessário que sua formação privilegie o desenvolvimento de uma postura científica, ética, política, didática e técnica. Isso equivale a dizer que a preparação deste profissional deve visar à aquisição de: a) um saber específico (científico), com base no estatuto epistemológico e no método investigativo do campo de conhecimento 
em que irá atuar; b) um saber pedagógico que conduza a uma reflexão sobre as práticas educativas, acerca do uso das tecnologias educacionais como suporte didático e das amplas questôes educacionais. Munido desse saber, o professor estará preparado para didaticamente reconstruir os conhecimentos que pretende ensinar; c) um saber cultural e político que promova o cultivo de "um patrimônio de conhecimentos e competências, de instituições, de valores e de símbolos, constituído ao longo de geraçôes e característico de uma comunidade humana particular" (Forquin, 1993 , p. 12). Esse domínio favorece a visão totalizante das relações entre a educação, a sociedade e a cultura, visão peculiar à formação do professor como um profissional culto e crítico; d) um saber transversal que estimule a multi, a inter e a transdisciplinaridade de conhecimentos, de informações e de metodologias, como estratégia de superação das inflexíveis fronteiras epistêmicas de cada campo específico, herdadas do modelo da racionalidade instrumental.

O processo de formação de professores necessita contemplar essa multiplicidade de conhecimentos e saberes, para que o estudante atinja a maturação interna (Honoré, 1980) e uma solidez de conhecimento e práticas que lhe confiram preparo teórico, habilidades para desenvolver o trabalho docente e certa emancipação profissional para começar a exercer a profissão.

Faço lembrar que as DCNP detalham a totalidade de conhecimentos e de práticas inerentes à formação do pedagogo, à medida que são explicitadas as possibilidades de elaboração do projeto político-pedagógico e de um currículo interdisciplinar do curso. Neste, devem ser respeitados três núcleos articuladores do conhecimento: o de estudos básicos, o de aperfeiçoamento e o de diversificação de estudos. Em face disso, as DCNP instigam as instituições formadoras a usar da liberdade para oferecer a formação do docente dos AIEF, da EI, assim como do pedagogo-pesquisador e do pedagogo-gestor, profissionais que poderão atuar também fora do sistema educacional.

Um curso de graduação que se ocupa do preparo do profissional da educação para seu ingresso no magistério é reconhecido por curso de formação inicial. Para a ANFOPE (1996, p. 21),

(...) é a formação inicial que vai habilitar o ingresso na profissão e deverá garantir um preparo específico, com um corpo de conhecimentos que permita ao profissional a condução do trabalho pedagógico e que, 
Políticas contemporâneas de formação de professores para os anos iniciais...

portanto, este profissional seja preparado para o domínio desse trabalho e para estabelecer relações que satisfaçam às necessidades para as quais ele foi formado.

Assim sendo, a formação inicial é formação "pré-serviço" feita em instituições especializadas. Essa expressão passou a vigorar a partir da 20a Reunião Anual da AnPed (1997), quando os pesquisadores do Grupo de Trabalho Formação de Professores concluíram que seu uso poderia evitar o equívoco, da maneira como aparece na LDB/1996, que em seu artigo 87, $\$ 4$, das Disposições Transitórias, admite como formação inicial do professor o "treinamento em serviço".

"Treinamento" foi uma modalidade de formação continuada presencial de inspiração tecnicista que norteou a "reciclagem" de professores. Faço notar que o dispositivo da LDB/1996 foi endereçado aos "professores" leigos atuantes na educação básica. O legislador teve a intenção de corrigir um desvio das políticas educacionais: os sistemas de ensino admitiram pessoas sem serem formadas, em conseqüência herdaram a obrigatoriedade de capacitá-las.

Reluto, todavia, em aceitar as atuais práticas de formação que, por preceito da LDB/1996, têm retomado procedimentos de "reciclagem" e de "treinamento em serviço", tão usados nos anos de 1970. Agora seu maior foco tem sido a educação a distância (EaD). Esses procedimentos são utilizados não para complementar os processos formativos presenciais dos professores, mas sim para substituir a formação inicial

É bastante cruel a realidade do EF que ainda conta com os chamados "professores" leigos. Ela foi mostrada pelo Censo Escolar (INEP/ MEC, 1995). Na região Norte, das pessoas que exerciam a função docente $37 \%$ eram leigas; na região Nordeste 30\%; na região CentroOeste 14\%; na região Sul 9\%; e na Sudeste 3\%. À época, os estados da Federação com maior quantidade de "professores" leigos eram: Maranhão (43,45\%), Piauí (39,5\%), Tocantins (39,6\%) e os de menores índices: São Paulo (0,5\%) e Rio de Janeiro (0,93\%). O Distrito Federal mantinha um índice insignificante $(0,06 \%)$. O número absoluto de funçóes docentes ocupadas por pessoas leigas na EF era assustador: 64.830. Isso feria o proclamado na LDB, que em seu artigo 62, define "como formação mínima para o exercício do magistério na Educação Infantil e nas quatro primeiras séries do Ensino Fundamental, a oferecida em nível médio, na modalidade Normal”. 
Para a formação desses "professores" leigos algumas iniciativas foram tomadas, entre elas, o Programa de Formação de Professores em Exercício (PROFORMAÇÃo), financiado pelo Banco Mundial. Como resultado desse Programa, em 2005 constatou-se que as regiōes beneficiadas apresentaram índices reduzidos de leigos na docência. $\mathrm{Na}$ região Norte, um percentual de $2,4 \%$, no Nordeste $1,9 \%$ e $0,8 \%$ na região Centro-Oeste.

Ressalto que ao PROFORMAÇÃO conjugam-se outros programas emergencais como a Licenciatura Plena Parcelada em Pedagogia. É certo que em termos quantitativos os resultados da LPP Pedagogia são surpreendentes, no entanto, inexistem registros sobre a qualidade da formação desse professor. Ao contrário, o sofrível desempenho dos estudantes da educação básica, comprovado pelo Sistema Nacional de Avaliação da Educação Básica (SAEB), e por outras formas de avaliação do alunado, pode indicar falta de qualidade na atuação dos egressos dos ditos programas emergencais de formação do professor.

Com relação ao ensino fundamental da $5^{\mathrm{a}}$ à $8^{\mathrm{a}}$ série e ao ensino médio, uma das alternativas foi a oferta de "cursos emergenciais" amparados pela Resolução CNE/CEB n. 2, de 26/6/1997. Esta dispõe sobre os programas especiais de formação pedagógica de docentes para as disciplinas do currículo do ensino fundamental, do ensino médio e da educação profissional em nível médio, portanto, possibilita aos portadores de diploma de quaisquer cursos superiores tornarem-se docentes.

Outros modelos de preparo professor previstos na LDB/1996 aceleraram a criação de instituições desobrigadas de realizar pesquisa, tais como: o Instituto Superior de Educação e a Escola Normal Superior. Desse modo, a formação extramuros da universidade, fica aligeirada, pois basta ao futuro professor ser treinado para transmitir conhecimentos em suas aulas. Diante desse quadro, a universidade consolida-se como instituição clássica de formação de professores na modalidade inicial compromissada com o desenvolvimento da pesquisa articulada, ao ensino e à extensão.

No que tange à educação continuada no Brasil, a modalidade é cada vez mais intensa por força das mudanças provocadas pelas reformas educacionais, amparadas pela LDB. A educação continuada de professores assenta-se na concepção de educação que se realiza ao longo da vida. Essa concepção penetra o espírito da LDB e é clarificada em seu 
Políticas contemporâneas de formação de professores para os anos iniciais...

artigo 10: "A educação abrange os processos formativos que se desenvolvem na convivência humana, na vida familiar, no trabalho, nas instituições de ensino e pesquisa, nos movimentos sociais e organizações da Sociedade Civil e nas manifestações culturais”. O artigo 67, inciso II, prevê: "Os sistemas de ensino promoverão aperfeiçoamento profissional continuado, inclusive com licenciamento periódico remunerado para esse fim”.

$\mathrm{O}$ atendimento ao direito de licença remunerada àquele que ingressa em uma formação continuada tem sido negligenciado pelos sistemas, apesar de fazer parte dos planos de carreira do magistério. Diante disso, a ANFOPE tem lutado para que tal prerrogativa seja conferida ao profissional e se torne um dever da agência contratante. Nessa busca, procura articular-se com os sindicatos e a Confederação Nacional dos Trabalhadores em Educação (CNTE), visando também a que o docente tenha reais condições de aprofundamento de estudos em nível de mestrado e doutorado, para o qual é indispensável licença financiada pela agência contratante, programada em seus projetos de desenvolvimento institucional e pedagógico, devendo ser concedida ao longo da carreira do professor.

Com efeito, no viII Encontro Nacional da ANFOPE (1996, p. 22) firma-se a idéia de que a formação continuada de professores é um processo ininterrupto, que deve:

(...) proporcionar novas reflexōes sobre a ação profissional e novos meios para o desenvolvimento do trabalho pedagógico, considerando que o conhecimento produzido e adquirido na formação inicial, na vivência pessoal e no saber da experiência docente deve ser repensado e desenvolvido na carreira profissional. (idem, ibid., p. 23)

A Associação admite que a formação continuada seja a distância, uma vez que, em virtude da vivência no quotidiano da escola básica e do domínio das novas tecnologias da comunicação, o professor não iniciante deve ter maturidade para se aperfeiçoar sem a presença do professor em um mesmo espaço e tempo de formação, características de cursos de EaD. Belloni (1999, p. 39) referenda essa posição, pois reconhece que cursos de EaD requerem um "modelo de aprendizagem apropriado a adultos com maturidade e motivação necessárias à autoaprendizagem e possuindo um mínimo de habilidades de estudo”. 
Já para Nóvoa (1991, p. 21), a formação continuada deve ser centrada na investigação e na reflexão. Em seus estudos, distinguiu dois "modelos" de formação continuada: os estruturantes, "organizados previamente a partir de uma lógica de racionalidade científica e técnica", e os construtivistas, "que partem de uma reflexão contextualizada para a montagem dos dispositivos de formação contínua, no quadro de uma regulação permanente das práticas e dos processos de trabalho".

$\mathrm{O}$ autor afilia-se ao segundo modelo e apresenta cinco teses sobre a formação continuada, das quais compartilho. A formação contínua deve: a) alimentar-se de perspectivas inovadoras; b) valorizar as atividades de autoformação participada e de formação mútua; c) alicerçar-se em uma reflexão na prática e sobre a prática; d) incentivar a participação de todos os professores em programas e em redes de colaboração; e) capitalizar as experiências inovadoras e as redes de cooperação existentes nos sistemas.

Além dessas concepções do autor, reporto-me a outra contribuição: a insistente formulação que cabe aos profissionais da educação assumirem.

(...) como produtores de sua profissão. Isto é, da mesma maneira que a formação não se pode dissociar da produção de saber, também não se pode alhear de uma intervenção no terreno profissional. As escolas não podem mudar sem o empenho dos professores; e estes não podem mudar sem uma transformação das instituiçôes em que trabalham. O desenvolvimento profissional dos professores tem que estar articulado com as escolas e os seus projetos. (Nóvoa, 1992, p. 28)

Com essa enunciação, o autor dá destaque à profissionalização docente, atribuindo aos professores a construção de sua profissão. Claro está, porém, que essa produção requer um processo coletivo, integrado aos projetos institucionais. Sendo assim, o professor terá a garantia de seu direito de desenvolver sua profissionalidade e seu profissionalismo, dos quais resulta, sem dúvida, uma melhor qualidade profissional e pessoal.

O caminho que o profissional percorre para tornar-se professor, sobretudo nos processos de formação e profissionalização, contribui de maneira relevante para a transformação da ocupação-professor em profissão-professor. Para tanto, é preciso o domínio de um conjunto de 
Políticas contemporâneas de formação de professores para os anos iniciais...

conceitos e práticas como uma forma de tornar nítida a identidade docente. Nesta trajetória, o profissional-professor poderá chegar à compreensão de que a profissionalidade e o profissionalismo constituem uma unidade dialética da profissionalização.

Ancorada em Sarmento (1998, p. 3), tenho o entendimento de profissionalidade como um conjunto de conhecimentos, de saberes, de capacidades de que o professor dispõe para o desempenho de suas atividades. Assim, profissionalidade consiste de uma complexa conjugação de requisitos profissionais indispensáveis àquele que busca uma formação para o futuro exercício no campo da docência. O profissionalismo, por sua vez, pode ser conceituado como o desempenho competente e compromissado de deveres e responsabilidades no exercício da profissão do magistério.

No Brasil, os profissionais da educação voltaram-se para a construção de sua profissionalização no interior de sua categoria de classe, assumindo uma identidade com, no mínimo, os seguintes traços específicos: a) possuir conhecimento e saberes, dominar procedimentos metodológicos e ter habilidades adquiridos em sua formação inicial e continuada; b) pautar-se por um código deontológico que lhe assegure uma postura ética; c) dedicar-se integralmente ao magistério; d) afiliar-se e participar efetivamente de entidades científicas e sindicais; e) reconhecer a importância dos procedimentos de avaliação e submeterse a eles para acesso à profissão e durante o exercício profissional; f) engajar-se na luta pela valorização da profissão-professor. Dentre tantos outros, esses traços mostram que são qualidades intrínsecas do profissionalismo: a docência como base da identidade de formação de todo profissional da educação; uma base comum nacional de formação inicial; a concepção de formação ao longo da vida, quer seja em espaços formais ou espaços não-escolares; a avaliação processual e contínua de desempenho profissional; um piso nacional unificado, traduzido em remuneração condigna, associada às boas condições de trabalho definidas em um plano de carreira.

Resultado dessa longa trajetória de formação, no século xx traçou-se um desenho da identidade do professor como profissional, mas a história da profissão docente, a regulação e a valorização socioeconômica do magistério no país continuam atravessados por processos contraditórios. Um exemplo é a coexistência de dois projetos de formação 
de professores assentados em concepções bastante distintas, como já foi mencionado neste artigo. Há, pois, de um lado, o projeto de formação que tem as bases epistemológicas na concepção histórico-social, fundamenta-se no conhecimento como eixo da formação, tem como paradigma a qualidade social da educação. Do lado de lá, existe um projeto de sociedade e de formação de professores que se inscreve em uma determinada concepção de economia de mercado, baseada na ideologia neoliberal e na refuncionalização do Estado para mínimo. Este projeto propugna a cultura da produção de saberes instrumentais e utilitários para a preparação de mão de obra tal como exigida pelo sistema capitalista. Para esse sistema, até a satisfação das necessidades elementares do homem sujeitam-se a critérios exclusivamente mercadológicos. Sendo assim, a tendência neo-tecnicista da educação e a teoria do neo-capital humano são seus ancoradouros e as competências consistem o eixo da formação inicial e continuada de professores.

No próximo item enfocarei dois aspectos concernentes à certificação de competências conferidas pelo Estado e à criação de um órgão, pela sociedade civil organizada em entidades, que venha a se materializar como conselho ou ordem de profissionais da educação.

\section{O contraditório nas questões intrínsecas ao profissionalismo docente}

A história da educação brasileira testemunha que a cisão entre os dois projetos de sociedade e de formação de professores supramencionados mostra-se irreversível, tal como se mostram antagônicas e bem delimitadas as classes sociais no Brasil capitalista: a dos privilegiados e a dos desafortunados.

A história testemunha também que a educação e a escola brasileira, herdeiras do modelo patrimonialista de Estado, ao longo de seu desenvolvimento mantêm esta dualidade: escola para ricos e escola para pobres, que aparece com nitidez nos projetos de formação de professores. Haja vista que dados estatísticos (INEP/MEC, 2006) demonstram a existência de escolas de formação de professores para ricos e para pobres. Isso fica comprovado quando os dados registram que em torno de $80 \%$ dos cursos de formação de professores concentra-se em instituiçóes de ensino superior particulares noturnas, cujo perfil acadêmico distancia-se da pesquisa e contempla o ensino. Estas instituições, a rigor, são procuradas pelo trabalhador-estudante. 
Políticas contemporâneas de formação de professores para os anos iniciais...

No tocante à formação do professor da educação básica e, em especial, do docente multidisciplinar para atuação nos AIEF, a realidade das instituições formadoras é uma as conseqüências do descaso das políticas educacionais, que vêm penalizando as instituiçôes públicas de ensino superior e condenam as escolas a apresentarem frágeis Índices de Desenvolvimento (IDEB). Nos últimos meses, os baixos índices têm municiado discursos da mídia e de políticos brasileiros que atribuem ao professor a falência da educação básica, como se a qualidade da formação e o exercício da docência fossem responsáveis pelas mazelas da opção pelo Estado mínimo, que procede o contingenciamento de recursos para as políticas sociais.

O Estado imputa à classe dos desafortunados o não-direito à educação, mas compensatoriamente faz proliferar políticas assistencialistas que sujeitam alguns "assistidos" à alienação, como denuncia Silva Jr. (2003, p. 79) ao caracterizar o Estado brasileiro como "reprodutor [servil ao capitalismo internacional], no que se refere à economia, e caritativo e fiscalizador, no que se refere à esfera social".

\section{Certificação de competências do professor dos AIEF}

Coerente com os princípios do projeto excludente, o Estado regulador aplica à formação de professores da educação básica o modelo de competências e excelência (qualidade total), cujo objetivo primordial é o atendimento às necessidades de modernização da economia e do desenvolvimento medidos pela produtividade. Esta, de acordo com Chauí (1999), é orientada por três critérios: Quanto se produz? Em quanto tempo produz? Qual o custo do que produz?

Tal modelo pauta-se no aligeiramento e flexibilidade da formação fora da universidade, reduz a quantidade de horas e a qualidade acadêmica, científica e cultural, porque o aligeiramento é induzido pela volatilidade das qualificaçóes requeridas pelo mercado. Descarta a relevante busca do conhecimento pelo profissional que se forma e destina-se a estimular uma frenética aquisição de certificados de qualidade incerta, com o objetivo primordial de "turbinar" os curricula vitae dos que aspiram a ingressar no mercado. Como sinalizam McLaren e Farahmandpur (2002, p. 84), esse modelo "está direcionando o sistema educacional público, cada vez mais, para um aparato duplamente 
sobreposto: um, enfileirando estudantes classificados por vidas de oportunidade limitada, e outro, reproduzindo o capital cultural e social da riqueza”.

Não é difícil identificar o produto desta lógica (de)formação: o preparo do professor centra-se no desenvolvimento de competências para o exercício técnico-profissional, consistindo, pois, em um preparo prático, simplista e prescritivo, baseado no aprendizado "imediato" do que vai ensinar, a fim de resolver problemas do cotidiano da escola. Asseguro que resolver esses problemas é importante, porém o aprendizado do "imediato" na maioria das vezes não tende a mobilizar suficientemente o conhecimento em busca de soluções. Nesta situação, o professor corre o risco de se valer de um "praticismo" sem limites, derivado de uma visão ativista da prática.

A certificação de competências do professor do ensino fundamental é uma das vertentes da arquitetada política educacional de Fernando Henrique Cardoso, configurando-se em perfeito mosaico de simultaneidade de ações: Parâmetros Curriculares Nacionais, Política do Livro Didático, DCN para a formação de professores e o sistema de avaliação de larga escala do desempenho de alunos, professores e instituições escolares.

Ropé e Tanguy denunciam que o uso da noção de competências serve para a "modelização" das atividades das instituiçõoes escolares, com a finalidade de medir individualmente as competências. Para desenvolver esse processo denominado "individualização" na formação, na profissionalização, no balanço de habilidades individuais:

(...) utilizam-se referenciais padronizados em que cada um supostamente executa uma série de "microtarefas", a fim de resolver o problema levantado em uma dada situação; porém o caráter abstrato dos referenciais de emprego e referenciais de formação não dá conta da verdadeira especificidade da tarefa a realizar. (...) A noção de competências autoriza e justifica, ao mesmo tempo, processos de racionalização, de codificação, de formalização, um desenvolvimento de técnicas relativamente gerais, assim como tentativas de modelização das atividades. (Ropé \& Tanguy, 1997, p. 202-203)

É evidente que o modelo padronizado de ações e aferição de resultados das políticas de formação de professores de FHC e também do Governo Lula encontra razões no significado aqui explícito de 
Políticas contemporâneas de formação de professores para os anos iniciais...

competências, com base em estudos do modelo educacional francês realizados por Ropé e Tanguy (1997). Durante a gestão de Paulo Renato de Souza, o MEC valeu-se de expertises estrangeiros, entre eles os da França, cuja especialidade era questões de currículo, formação de professores e certificação de competências.

Não se trata também de mera coincidência, a relatora ${ }^{4}$ do Parecer CNE/CP n. 9, de 8/5/2001, e da Resolução CNE/CP n. 1, de 18/2/ 2002, que instituíram as DCN para a formação de professores da educação básica e a certificação de competências, na condição de deputada federal do mesmo partido de FHC, foi autora do PL n. 1.172/2003, que dispõe sobre as "Diretrizes da política nacional de formação, certificação e valorização do magistério público”.

Na Resolução CNE/CP n. 1/2002 (art. 16) está prevista a organização de um sistema de certificação de competências da educação básica, coordenada pelo MEC em regime de colaboração "com o CNE, o Conselho Nacional de Secretários Estaduais de Educação, o Fórum Nacional de Conselhos Estaduais de Educação, a União Nacional dos Dirigentes Municipais de Educação e representantes de Conselhos Municipais de Educação e das associações profissionais e científicas".

Curioso é que integrantes da equipe gestora do MEC no governo de FHC atuavam como conselheiros no CNE, defendendo a criação do sistema de certificação e, mediante uma trama ardilosamente tecida em busca de consensos, encontraram respaldo na Comissão de Educação e Cultura da Câmara dos Deputados (CEC), sob o pretexto de que tal sistema seria uma estratégia de valorização e qualificação do professor.

Uma integrante da mencionada equipe MEC/FHC, defensora da certificação de competências do professor da educação básica, hoje ocupa o cargo de secretária de Estado da Educação de São Paulo e faz sérias acusações ao corpo docente da rede pública. A esse corpo docente é atribuída a culpa de manter um corporativismo sindical exacerbado em defesa da isonomia salarial que "contribui para a acomodação dos professores em uma zona de mediocridade", porque reivindicam "aumento de salário indiscriminado para professor ruim, desinteressado ou que mal aparece na escola" (Castro, 2008, p. 9-12).

As críticas detonadas por Castro (2008) desqualificam, em particular, as agências formadoras do professor multidisciplinar dos AIEF e 
do professor da educação infantil quando a secretária reporta-se a um polêmico desejo de mundo ideal, afirmando:

(...) eu fecharia todas as faculdades de pedagogia do país, até mesmo as mais conceituadas, como a USP e a UNICAMP, e recomeçaria tudo do zero. Isso porque se consagrou no Brasil um tipo de curso de Pedagogia voltado para assuntos exclusivamente teóricos, sem nenhuma conexão com as escolas públicas e suas reais demandas. (Castro, 2008, p. 12)

Como fiel escudeira do projeto de sociedade, educação, formação de professores e escola básica que se fundamenta na tendência neotecnicista da educação, Castro elegeu a "pedagogia das competências”, desde a última década do século passado, como eixo nuclear de sua atuação como gestora da "coisa pública" em uma res-publicae. Em seu cargo atual sente-se no direito de agredir ainda mais a "coisa pública" ao traçar o perfil do ensino de pouca qualidade ministrado nas faculdades de educação, sem poupar as mais conceituadas do Estado de São Paulo. O problema é que Castro não mostra evidências científicas acerca de sua opinião, que aqui transcrevo:

As faculdades de educação estão demais preocupadas com um discurso ideológico sobre as funções transformadoras do ensino. Elas acabam deixando em segundo plano evidências científicas sobre as práticas pedagógicas que de fato funcionam no Brasil e no mundo. (Castro, 2008, p. 12).

Essa crítica da secretária não causa estranheza às entidades do campo da educação, defensoras das faculdades de educação, do curso de Pedagogia e resistentes à organização do sistema referido no artigo 16 das DCN para a formação de professores da educação básica. Castro alinha-se ao projeto de sociedade e de formação de professores que está do lado de lá do "cabo-de-guerra", puxado na outra ponta pelas entidades da educação.

$\mathrm{Na}$ verdade, atitude surpreendente foi a do ministro Cristovam Buarque, do Governo Lula, que instituiu o Sistema Nacional de Certificação e Formação Continuada de Professores, pela Portaria n. 1.403, de 9/6/2003. Tal qual como Castro (2008), Buarque deu ênfase ao mérito profissional no processo de certificação (art. $1^{\circ}$, inciso I), que compreende "O Exame Nacional de Certificação de Professores, 
Políticas contemporâneas de formação de professores para os anos iniciais...

por meio do qual se promovem parâmetros de formação e mérito profissionais; (...)".

A validade do Certificado Nacional de Proficiência Docente foi prevista para cinco anos (art. 17). Conforme artigo $6^{\circ}$, da Portaria n. $1.403 / 2003$, o MEC proporá, por meio de um PL, a Bolsa Federal de Incentivo à Formação Continuada, a ser concedida a todo professor certificado, em exercício nas redes públicas de ensino. Os exames de certificação deveriam iniciar-se com os professores de séries ou ciclos iniciais do ensino fundamental, candidatos prioritários aos programas de formação continuada.

O contraditório, neste caso, reside na exigência do certificado de competências para que o professor do ensino fundamental, em exercício na escola pública, possa se candidatar aos programas de formação continuada com bolsa federal de incentivo, uma vez que se confronta com o disposto no artigo 67 da LDB: os sistemas de ensino devem assegurar a valorização dos profissionais da educação mediante "ingresso exclusivamente por concurso público de provas e títulos (inciso I) [e] "aperfeiçoamento profissional continuado, inclusive com licenciamento periódico remunerado para este fim” (inciso II).

Diante dessa contradição, indago: Em que medida o Certificado de Proficiência Docente contribuirá para a valorização do magistério, considerando que os dispositivos legais acerca deste assunto reiteradamente são aprovados porque priorizam essa valorização?

A meu ver, esse processo é um instrumento de balanço das competências por meio de testes padronizados aplicados em larga escala sem considerar a cultura da escola, da comunidade e do professor, visando a satisfazer necessidades do Estado regulador, com reflexos negativos tanto na profissionalidade quanto no profissionalismo como unidade dialética da profissionalização docente.

As propostas de Buarque não foram aplicadas, em conseqüência de sua demissão pelo presidente da República, mas o PL n. 1.172/ 2003 continua em tramitação na CEC/Câmara, sendo retomado por força de desarquivamento pela autora, em 2/10/2007.

Uma análise cuidadosa do mencionado PL revela a mudança de eixo da organização de um Sistema Nacional de Certificação de Competências para a elaboração de Diretrizes de uma Política Nacional de Formação, Certificação e Valorização do Magistério Público a cargo do 
MEC, "em colaboração com os sistemas de ensino dos estados, municípios e Distrito Federal" (art. $1^{\circ}$ ), o que obviamente impede a colaboração das entidades da sociedade civil do campo educacional.

Na tramitação deste PL em discussão houve uma "feliz" coincidência que favoreceu a propositora: a relatoria recaiu no deputado Paulo Renato de Souza, ministro da Educação, responsável pelas políticas educacionais fulcradas no neoliberalismo. É evidente que o relator acatou o pleito da companheira de partido político, pois estão reciprocamente afinados em ideologias, valores, ideais, objetivos e metas. Coube um substitutivo do relator ao PL com a aprovação da Lei n. 11.273, de 6/2/2007, que autorizou a concessão de bolsas de estudo e de pesquisa a participantes de programas de formação inicial e continuada de professores para a educação básica. Essa lei, entretanto, foi alterada pela de n. 11.502, de 11/7/2007, que modifica as competências e a estrutura organizacional da fundação Coordenação de Aperfeiçoamento de Pessoal de Nível Superior (CAPES). Talvez tenha sido esta razão que levou o relator a retirar de pauta da Comissão o PL n. 1.172/2003, em $19 / 12 / 2007$.

A CNTE manifestou-se sobre o assunto em nota pública, durante debates ocorridos, em 2007, na CEC/Câmara:

Do ponto de vista da certificação predominam elementos que pretendemos superar em nosso modelo educacional, como a lógica da formação individualizada e competitiva, a predominância do conceito de meritocracia, a responsabilização segmentada dos educadores, a desresponsabilização dos gestores para com a formação continuada (e inicial), a desconsideração do projeto político-pedagógico como indutor da qualidade, a omissão à gestão democrática e a imprevisibilidade dos mecanismos de carreira. (CNTE, 2007, p. 2)

Resta esperar acertadas propostas e ações do CTC/EB, decorrentes da reconfiguração da CAPES, eliminando de uma vez por todas a certificação de competências do professor do ensino fundamental e acionando a proposta de criação de um Sistema Nacional de Formação de Professores.

Outra questão candente no que tange à profissionalização do magistério, ainda a ser tratada, é a criação de um órgão regulador da profissão-professor. 


\section{Conselho ou ordem reguladora da profissão}

Apesar desta discussão não ser exclusiva da ANFOPE, optei por pesquisar em seus documentos os registros sobre a criação de um Conselho Nacional de Professores. Fiz opção em virtude de estar envolvida nos debates acerca do assunto e de participar das comissóes redatoras dos documentos finais dos encontros nacionais realizados desde 1983 por essa Associação, tendo em vista que milito ininterruptamente no movimento e permaneço participante pari passu de suas reivindicaçóes, lutas, conquistas e reveses.

De fato, a primeira idéia da constituição de um conselho regulador da profissão pela sociedade civil surgiu entre os participantes do Encontro Nacional, que teve lugar em Belo Horizonte, em 1983. Logo, essa discussão faz parte da história do movimento dos profissionais da educação. Vincula-se à luta pela valorização e profissionalização do magistério e à necessidade de fiscalização nas instituiçōes formadoras, porém uma fiscalização apartada do modelo regulador do aparelho estatal.

Naquele evento, a Associação Nacional dos Docentes do Ensino Superior (ANDES), hoje sindicato, manifestou-se contrária à criação de tal conselho. Desde então, a ANFOPE manteve-se silente em relação ao assunto.

Em 1994, durante o VI Encontro Nacional realizado em Niterói, o debate sobre a criação do conselho foi retomado e a ANDES, juntamente com o Sindicato de Professores do Rio de Janeiro, encaminharam contra esta proposta, que foi acatada pela maioria dos participantes diante do argumento de que o sindicato, e não o conselho, constituiria o espaço de luta da valorização do professor.

Durante o Ix Encontro (Campinas, 1998) e o x (Brasília, 2000), época marcada por mudanças previstas na LDB vigente, o debate voltou à tona. Nesses encontros, pesquisadores expuseram resultados sobre "a profissionalização docente enfocada pela dimensão ética". A apreensão deste objeto requereu dos investigadores algumas problematizaçóes: "Qual o papel que viria desempenhar um conselho profissional?" (Veiga, Araújo \& Kapuziniak, 2005, p. 10-11). Que argumentos estão a favor ou contra a criação de um conselho ou de uma ordem profissional da docência? 
Veiga e colegas, para desenvolverem a pesquisa, analisaram 24 códigos de ética, abrangendo 30 profissóes. Este estudo mapeou argumentações a favor e contra a existência de um conselho da profissãoprofessor. A favor: proteção do interesse público-usuário pela presença atuante da entidade; insuficiência do sistema educacional em assegurar a profissionalização da docência que ganha qualidade quando a atenção é mais voltada para a ética do que para normas prescritas pelo MEC; função complementar e não superposta às atribuiçôes do sindicato; revitalização do movimento dos profissionais em busca da cidadania nos próprios locais de trabalho; controle do exercício profissional de modo preventivo. Contra: interferência nas atribuições sindicais; destina-se a vigiar e punir quem desrespeita código e normas aprovados coletivamente; risco de ter conselhos fragmentados diante da multiplicidade de subáreas e níveis de atuação do magistério. A posição contrária expressa pela CNTE, no x Encontro, foi a de que um conselho tem conotação burocrática e a valorização do professor é política (ANFOPE, 2000).

$\mathrm{Na}$ esteira desses debates, a ANFOPE manifestou suas inquietaçōes quanto ao seguinte: Que princípios da formação devem ser balizadores da atuação profissional? Qual a ética que orienta o exercício profissional dos professores? Com o fim da tutela do MEC, a quem cabe "fiscalizar" a profissão? Esta fiscalização e controle são efetivamente necessários? (idem, ibid., p. 42).

Os debates posteriores constataram que, embora os sindicatos fossem parceiros de luta pela valorização da profissão, sozinhos não teriam condições de conquistá-la, premissa consiste para a busca de outras soluções. Além de dar continuidade aos estudos acerca da criação de um conselho, as entidades acadêmicas e científicas deveriam manter estreita relação com os sindicatos e outras entidades interessadas, como aconteceu no Fórum Nacional em Defesa da Educação Pública na LDB, espaço político legitimamente representado pela Sociedade Civil organizada que agregava diversas entidades do campo da educação em torno de um interesse comum: defesa da escola pública, laica, gratuita e de qualidade social em todos os níveis e modalidades de ensino.

Neste ínterim, dois episódios provocados por setores conservadores da educação interferiram na continuidade das discussões sobre o conselho: a) o projeto de regulamentação da profissão do pedagogo, PL 
Políticas contemporâneas de formação de professores para os anos iniciais...

n. 4.746/1998, do deputado Arnaldo de Sá; b) a criação no MEC/InEP, da Agencia Nacional de Educação, sob a presidência de Maria Helena Guimarães de Castro, com a finalidade de avaliar e regular da educação básica ao ensino superior (graduação), que teve, porém, duração efêmera, sendo substituída no governo Lula por novos programas do INEP. Quanto ao PL n. 4.746/1998, coube ao relator Átila Lira (PI) apresentar substitutivo, depois arquivado. Creio que a causa desde encaminhamento tenha sido a homologação das DCNP, pois o conteúdo do PL se distanciava muito do perfil profissional do pedagogo preconizado pelas Diretrizes. De acordo com as DCNP, o licenciado em Pedagogia terá como base da identidade profissional a docência nos anos iniciais do ensino fundamental e educação infantil. Poderá também o curso formar o pesquisador e gestor educacional para atuar na escola e em espaços não escolares, bem como na educação profissional na área de serviços e apoio escolar.

Atualmente, dois fatos poderão recolocar na ordem do dia as discussões sobre as políticas de formação, regulação e valorização do magistério e que implicam o exame da proposta da criação do Conselho de Professores, a ser feito tanto pelo MEC, quanto pela Câmara dos Deputados. São eles: a) a vigência da Lei n. 11.502/2007 (cf. art. 1o,\$ 2o); b) o PL n. 2.667, de 19/12/2007, do deputado Waldir Maranhão (MA).

A Lei n. 11.502/2007 (cf. art. 1\% \$ 20), ao criar o CTC/EB, incorporou às finalidades da CAPES a de fomentar a formação inicial e continuada de profissionais de magistério para a educação básica, a elaboração da política de formação e a organização do Sistema Nacional de Formação de Profissionais da Educação. Os membros do CTC/EB foram empossados em 14/2 deste ano. A correlação de forças é favorável à valorização e profissionalização docente e será cada vez mais intensa, pois diversos companheiros do movimento de educadores integram esse Comitê.

O pL n. 2.667, de 19/12/2007, dispõe sobre a regulamentação da profissão de Magistério da Educação Básica e autoriza a criação do Conselho Federal e dos Conselhos Regionais do Magistério da Educação Básica, encontra-se desde 14/2/2008 na CTASP/Câmara. Caso seja aprovado e transformado em lei, colidirá com atribuições da Câmara de Educação Básica do CNE e com os propósitos das entidades educacionais que lutam pela criação de uma política nacional de formação 
de professores que articule formação inicial e continuada com condições dignas salariais e de trabalho e a organização do Sistema Nacional de Formação de Professores. Na verdade, a tramitação do projeto em tela prenuncia fortes reaçóes contrárias, tanto das entidades quanto do poder instituído.

\section{Considerações finais}

À luz das reflexões aqui feitas, atrevo-me a enunciar algumas consideraçôes: a) a quantidade de matrículas que atingiu $96 \%$ da população escolarizável, no ensino fundamental, não resultou em qualidade no desempenho do alunado, evidenciado pelo IDEB. Diante desse fato, faço lembrar que quantidade para muitos e qualidade para poucos não significa que o cidadão brasileiro tenha direito ao ensino fundamental previsto como direito subjetivo pela Constituição Brasileira (Gentili, 1994); b) a histórica dualidade da educação e da escola permanece: poucos têm o privilégio de inclusão no ensino fundamental de qualidade social e à maioria da população é negado este direito; c) o Estado mínimo brasileiro vem cavando um fosso entre o que consta da legislação e as ações emanadas das políticas educacionais; d) as políticas educacionais de formação e valorização dos professores do ensino fundamental dos governos FHC (1994-2001) e Lula (2002-2007) acercam-se da qualidade total e desprezam a qualidade social; e) os exames de certificação de competências do professor tenderão a permanecer inoperantes e talvez sejam eliminados, a depender das políticas de formação inicial e continuada de profissionais da educação básica, atribuídas à nova CAPES; f) a formação inicial de professores para os AIEF e educação infantil tiveram um avanço com as DCNP, no que ser refere ao corpus doutrinário construído pelo CNE, porquanto incorporou contribuições do movimento de educadores e traçou nítidos contornos à identidade do curso de Pedagogia e do pedagogo; g) à medida que as entidades educacionais em rede discutem resultados de pesquisas sobre a polêmica criação de um Conselho de Profissionais da Educação, deputados federais apresentam projetos para a regulamentação da profissão do pedagogo (1998), certificação de professores (2003), regulamentação da profissão do magistério da Educação Básica e criação de seus órgãos reguladores, como conselhos nacional e regionais (2007). 
Políticas contemporâneas de formação de professores para os anos iniciais...

Por fim, devo destacar que as próprias considerações finais estão plenas de conflitos, o que permite concluir que a contradição é uma categoria desvelada pela realidade, pelo menos, quando os estudos retratam as políticas contemporâneas de formação e profissionalização do professor dos anos iniciais do ensino fundamental.

\section{Recebido em março de 2008 e aprovado em outubro de 2008.}

\section{Notas}

1. Segundo a Lei de Diretrizes e Bases da Educação Nacional (Lei n. 9.394/1996, art. 62 e 63) e o conjunto normativo formado pelo Parecer CNE/CP n. 5, de 13/12/2005, pelo Parecer CNE/CP n. 3, de 21/2/2006, e pela Resolução CNE/CP n. 1, de 15/5/2006, que instituiu as Diretrizes Curriculares do Curso de Pedagogia, Licenciatura Plena.

2. Quanto à noção de competências, Ropé e Tanguy (1997, p. 202) constatam que "um consenso implícito autoriza o uso que se faz dessa noção aqui e ali, a saber, uma centralização sobre os indivíduos e sua necessária mobilidade e adaptabilidade. Trata-se sempre de individualização: na formação, nas avaliações, nos balanços de competências". Na acepção de Perrenoud (1997, p. 8), competência é "uma capacidade de agir eficazmente em um determinado tipo de situação, apoiada em conhecimentos, mas sem limitar-se a eles". Prossegue o autor explicando que "ser competente implica saber produzir um número infinito de ações, sem estarem programadas".

3. Essa idéia de rede é explicitada por Boaventura de Souza Santos como uma forma de reorganização alternativa chamada "globalização solidária", que se contrapõe à "globalização neoliberal". A organização em rede, ao mesmo tempo, fortalece a legitimidade de cada associação e garante especificidades próprias. A "globalização solidária" possibilita superar o isolacionismo de associações que acabam, na maioria dos casos, "reivindicando colectivamente benefícios de que só individualmente se apropriam” (Santos, 2004, p. 94).

4. Refiro-me à conselheira, no CNE, professora doutora Raquel Figueiredo Alessandri Teixeira, deputada federal (PSDB).

\section{Referências}

ALARCÃO, I. (Org.). Escola reflexiva e nova racionalidade. Porto Alegre: ARTMED, 2001.

ANFOPE. Coletânea dos documentos finais dos Encontros Nacionais: I ao VI. Rio de Janeiro: UfF, 1993.

ANFOPE. Documento final do VIII Encontro Nacional. Belo Horizonte, 1996. (mimeo.) 
ANFOPE. Documento final do X Encontro Nacional. Brasília, DF, 2000. (mimeo.)

BELLONI, M. L. Educação a distância. Campinas: Autores Associados, 1999.

BIANCHETTI, R. Modelo neoliberal e politicas educacionais. Campinas: Autores Associados, 1997.

BRASIL. Lei n. 9.394, de 20/12/1996. Estabelece as diretrizes e bases da educação nacional. In: BRZEZINSKI, I. (Org.). LDB interpretada: diversos olhares se entrecruzam. 10. ed. São Paulo: Cortez, 2007. p. 246-266.

BRASIL. Lei n. 11.274, de 6/2/2006. Altera a redação dos art. 29, 30, 32 e 87 da Lei n. 9.394, de 20/12/1996, que estabelece as diretrizes e bases da educação nacional, dispondo sobre a duração de 9 (nove) anos para o Ensino Fundamental, com matrícula obrigatória a partir dos 6 (seis) anos de idade. Disponível em: <http://www.planalto.gov.br>. Acesso em: 15 dez. 2007.

BRASIL. Lei n. 11.502, de 11/7/2007. Modifica as competências e a estrutura organizacional da fundação Coordenação de Aperfeiçoamento de Pessoal de Nível Superior. Disponível em: <http:// www.planalto.gov.br>. Acesso em: 31 jan. 2008.

BRASIL. CÂMARA DOS DEPUTADOS. Projeto de Lei n. 4.746, de 13/8/1998. Dispóe sobre a regulamentação da profissão do pedagogo. Disponível em: <http://www2.camara.gov.br>. Acesso em: 15 jan. 2004.

BRASIL. Projeto de Lei n. 1.172, de 3/6/2003. Dispõe sobre as Diretrizes da política nacional de formação, certificação e valorização do magistério público. Disponível em: <http://www2.camara.gov.br>. Acesso em: 15 jan. 2008.

BRASIL. Projeto de Lei n. 2.667, de 19/12/2007. Dispõe sobre a regulamentação da profissão de Magistério da Educação Básica e autoriza a criação do Conselho Federal e dos Conselhos Regionais do Magistério da Educação Básica. Disponível em: <http://www2.camara.gov.br>. Acesso em: 15 jan. 2008.

BRASIL. MEC. Portaria n. 1.403, de 9/6/2003. Institui o Sistema Nacional de Certificação e Formação Continuada de Professores. Diário 
Políticas contemporâneas de formação de professores para os anos iniciais...

Oficial da República Federativa do Brasil, Brasília, DF, n. 110, p. 50, 10 jun. 2003.

BRASIL. INEP. Sinopses Estatísticas da Educação Básica: 1991-1995. Disponível em: <http://www.inep.gov.br/download/catalogo_dinamico/ estatisticas/mioloSinopse1991-1995.pdf>. Acesso em: 7 jul. 2007.

BRASIL. Cadastro das instituições de educação superior. Disponível em: <http//:www.educacaosuperior.inep.gov.br>. Acesso em: 7 jul. 2007.

BRASIL. MEC/CNE/CEB. Resolução n. 2, de 26/6/1997. Dispõe sobre os programas especiais de formação pedagógica de docentes para as disciplinas de formação pedagógica de docentes para as disciplinas do currículo do Ensino Fundamental, do Ensino Médio e da Educação Profissional em nível médio. Diário Oficial da República Federativa do Brasil, Brasília, DF, n. 133, p. 14.926, 15 jul. 1997.

BRASIL/MEC/CNE. Parecer CNE/CP n. 9, de 8/5/2001. Diretrizes Curriculares Nacionais para a Formação de Professores da Educação Básica, em nível superior, curso de licenciatura, de graduação plena. Diário Oficial da República Federativa do Brasil, Brasília, DF, p. 31, 18 jan. 2002. Seção 1.

BRASIL. Resolução CNE/CP n. 1, de 18/2/2002. Institui Diretrizes Curriculares Nacionais para a Formação de Professores da Educação Básica, em nível superior, curso de licenciatura, de graduação plena. Diário Oficial da República Federativa do Brasil, Brasília, DF, p. 31, 9 abr. 2002. Seção 1 .

BRZEZINSKI, I. Pedagogia, pedagogos e formação de professores: busca e movimento. 1994. Tese (doutorado) - Faculdade de Educação. Universidade de São Paulo, São Paulo.

BRZEZINSKI, I. (Coord.). Formação de profissionais da educação (1997-2002). Brasília, DF: MEC/INEP, 2006. (Série Estado do Conhecimento, v. 10)

BRZEZINSKI, I. et al. Diretrizes curriculares do curso de Pedagogia no Brasil: disputas de projetos no campo da formação do profissional da educação. Educação \& Sociedade, Campinas, v. 27, n. 96, p. 819842, out. 2006 (Especial). 
CARREIRA, T. Marcas de identidade e qualidade em educação. In: CONGRESSO DA SOCIEDADE PORTUGUESA DE CIÊNCIAS DA EDUCAÇÃO "INVESTIGAR E FORMAR EM EDUCAÇÃO”, 6., 1999, Porto. Anais... Porto: Fundação Caloustre Gulbenkian/Instituto de Inovação Educacional/Fundação para a Ciência e Tecnologia, 1999. p. 37-40.

CASTRO, M.H.G. Premiar o mérito. Entrevista concedida a Mônica Weinberg. Veja, ano 41, n. 6, São Paulo, p. 9-13, 13 fev. 2008.

CHAUI, M. A universidade em ruínas. In: Trindade, H. (Org.). Universidade em ruinas: na república dos professores. 3. ed. Petrópolis: Vozes/CIPEDE, 1999. p. 211-222.

CNTE. Posição da CNTE sobre os Projetos de Lei n. 1.172/2003, 1.088/ 2007 e 1.126/2007, que tratam, respectivamente, da Certificação dos Profissionais do Magistério e do Currículo Minimo para a Educação Básica. (Nota Pública) Disponível em: <http://www.cnte.org.br>. Acesso em: 3 fev. 2008.

COÊLHO, I.M. Formação do educador: dever do Estado, tarefa da universidade. In: Bicudo, M.A.V.; Silva Junior, C.A. Formação do educador. São Paulo: UNESP, 1996. p. 17-43.

CONARCFE. Documento final do I Encontro Nacional do Projeto de Reformulação dos Cursos de Preparação de Recursos Humanos para a Educação. Belo Horizonte, 1983. (mimeo.)

DINDO, R. Boa educação depende da universidade. Disponível em: <http://www.portal.mec.gov.br>. Acesso em: 3 jul. 2007.

FERRY, G. Le trajet de la formacion. Paris: Dunod, 1987.

FERNANDES, A.T. Sociologia e sócio-lógica. Porto: Brasília, 1985.

FREITAS, H.C.L. Pronunciamento da ANFOPE na audiência pública sobre a escola de 9 anos. Campinas, 5/12/2006. Disponível em: <http:/ /www.lite.fae.unicamp.br/anfope>. Acesso em: 12 mar. 2007.

FORQUIN, J-C. Escola e cultura: as bases sociais e epistemológicas do conhecimento escolar. Porto Alegre: Artes Médicas, 1993.

GARCIA, C.M. Formação de professores: para uma mudança educativa. Porto: Porto, 1999. 
Políticas contemporâneas de formação de professores para os anos iniciais...

GENTILI, P.A.A. O discurso da "qualidade" como nova retórica conservadora no campo educacional. In: Gentili, P.A.A.; Silva, T.T. (Org.). Neoliberalismo, qualidade total e educação: visões críticas. Petrópolis: Vozes, 1994. p. 111-177.

HONORÉ, B. Para una teoría de la formación. Madri: Narcea, 1980. KOSIK, K. Dialética do concreto. 2. ed. Rio de Janeiro: Paz \& Terra, 1976.

McLAREN, P.; FARAHMANDPUR, R. Pedagogia revolucionária na globalização. Trad. de Marcia Moraes. Rio de Janeiro: DP\&A, 2002.

NÓVOA, A. Concepções e práticas de formação contínua de professores. In: CONGRESSO NACIONAL DE FORMAÇÃO CONTÍNUA DE PROFESSORES: REALIDADES E PERSPECTIVAS, 1., 1991, Aveiro. Anais... Aveiro: Universidade de Aveiro, 1991. p. 15-38.

NÓVOA, A. A formação de professores e profissão docente. In: NóvOA, A. Os professores e a sua formaçāo. Lisboa: Dom Quixote, 1992.

PERRENOUD, P. Construire dés competénces dès l'école. Paris: ESF Èditeur, 1997.

ROPÉ, F.; TANGUY, L. (Org.). Saberes e competências: o uso de tais noções na escola e na empresa. Trad. de Patrícia Chittoni Ramos et al. Campinas: Papirus, 1997.

SARMENTO, M.J. Profissionalidade. Porto: Porto, 1998. (Dossier Rumos)

SAVIANI, D. Os saberes implicados na formação do educador. In: Bicudo, M.A.V.; Silva Junior, C.A. Formação do educador. São Paulo: UNESP, 1996. p. 145-155.

SAVIANI, D. Pedagogia: o espaço da educação na universidade. Cadernos de Pesquisa, São Paulo, v. 37, n. 130, p. 99-134, jan./abr. 2007.

SILVA JR., J.R. Reformas do Estado e da educação e as políticas públicas para a formação de professores a distância: implicações políticas e históricas. Revista Brasileira de Educação, São Paulo, n. 24, p. 7894, set./dez. 2003.

VEIGA, I.A.; ARAÚJO, J.C.; KAPUZINIAK, C. Docência: uma construção ético-profissional. Campinas: Papirus, 2005. 